PAPER

CrossMark

\title{
Synthesis and characterization of novel high temperature structural adhesives based on nadic end capped MDA-BTDA-ODA copolyimide
}

16 August 2018

ACCEPTED FOR PUBLICATION

17 August 2018

PUBLISHED

31 August 2018

\author{
Oktay Acar ${ }^{1,2}$, Serhat Varis ${ }^{1}$, Tuğba Isık ${ }^{2}$, Seha Tirkes ${ }^{3}$ and Mustafa M Demir ${ }^{2}$ (1) \\ 1 Composite and Polymeric Materials Division, TUBITAK-SAGE, Mamak, Ankara 06261, Turkey \\ 2 Department of Materials Science and Engineering, İzmir Institute of Technology, Urla, İzmir 35430, Turkey \\ Department of Chemical Engineering and Applied Chemistry, Atilim University, İncek, Ankara 06836, Turkey \\ E-mail: mdemir@iyte.edu.tr
}

Keywords: adhesive, high temperature, mechanical properties, polyimide, thermoset

Supplementary material for this article is available online

\begin{abstract}
A series of novel copolyimide structural adhesives were synthesized using 4,4'-diaminodiphenylmethane (MDA), 3,4'-oxydianiline (ODA) and 3,3',4,4'-benzophenonetetracarboxylic acid dianhydride (BTDA) as co-monomers, and nadic anhydride as an end cap reagent. The adhesives with different MDA and ODA contents were examined in terms of their structure, thermal stability, mechanical properties, and adhesive performance. They have glass transition temperatures $\left(T_{g}\right)$ about $400{ }^{\circ} \mathrm{C}$, with thermal stability up to $500^{\circ} \mathrm{C}$. The effect of diamine monomer compositions on adhesion performance and processability of the copolyimides were studied. The copolyimides exhibited adhesion strength up to $16.3 \mathrm{MPa}$ at room temperature. Nadic end capped MDA-BTDA-ODA copolyimide resins gained adjustable and controllable processability with the addition of ether bridged aromatic segments. The copolyimide adhesive with equimolar composition of MDA:ODA is distinguished form the both commercial PMR-15 and LARC RP-46 polyimides in terms of its better processability and mechanical performance.
\end{abstract}

\section{Introduction}

Lightweight materials provide considerable advances by improving the fuel efficiency and performance of various vehicles. Aluminum and titanium alloys, and fiber reinforced polymer composites have been extensively used as structural materials due to their superior mechanical properties along with their lightweight features [1-4]. Different kinds of assembling techniques such as adhesive bonding, fastening and welding are used in order to join structural materials together. Adhesive bonding has been preferred to integrate the polymeric and metallic nature of materials because of their superior fatigue resistance, low weight, low cost, and large tolerance to damage [5-7].

Indeed, most adhesives are polymer based, such as epoxies, phenolics, bismaleimides and acrylics [8]. Therefore, they have poor heat-resistant properties, which often lead to oxidation and failure at hightemperatures [7,9]. The requirements of having thermal stability, good mechanical properties and retention capability at elevated temperatures render the production of aromatic polymers, which are composed of aromatic rings linked to various functional groups [10]. Aromatic polyimides (PI) exhibit amazing thermooxidative stability, low dielectric constant, high electrical resistivity, high glass transition and melting temperatures, and chemical stability [11]. However, the processing of polyimides is challenging due to their rigid polymer backbones and strong chain interactions that bring along insolubility and infusibility [12, 13].

PI adhesives are promptly concerned in automobile, railway transport, aerospace and microelectronic industries [14]. The fabrication of PIs starts with the production of the prepolymer consisting of polyamic acid solution in polar solvents such as $\mathrm{N}$-methylpyrrolidone, $\mathrm{N}, \mathrm{N}$ - dimethylformamide or dimethylacetamide. Polyamic acid is produced by the reaction of diamine with dicarboxylic acid diester as comonomer, and they are subsequently converted to polyimides by thermal or chemical treatments [15]. The first commercial polyimide, Kapton $^{\mathrm{TM}}$ was developed by DuPont in 1955 [16]. Then, NASA Langley Research Centre developed the high 
performance thermoset polyimide PMR-15 in 1970's [17]. Because of its low cost for manufacturing, and excellent performance at high temperatures, PMR-15 has shown to be promising candidate for hightemperature structural adhesives [18-23]. However, PMR-15 has both limited processing capability and flexibility problems because of its rigid backbone structure [17]. LARC RP-46, an alternative polymide homopolymer to PMR-15, was developed by NASA Langley Research Centre [24]. LARC RP-46 resin incorporates flexible 3,4' -oxydianiline (3,4'-ODA) monomers instead of methylenedianiline moieties in PMR15. Pater's group reported that introduction of $3,4^{\prime}$-ODA into PMR structure offers improved processability due to the increase in resin flow $[24,25]$. Hou et al proposed that replacing the methylenedianiline moieties in PMR15 with 3,4'-oxydianiline improves the structural durability, higher composite mechanical properties at high temperatures [26].

The challenge of enhancing PI's processability can be eliminated by some approaches such as the introduction of flexible ether linkages, fluorinated groups, bulky substituents and copolymerization [13, 27-33]. PIs could exhibit low thermo-mechanical properties when they were synthesized from flexible monomers. While 3,3',4,4' -benzophenonetetracarboxylic acid dianhydride (BTDA), 4,4'-hexafluoroisopropylidene diphthalic anhydride (6FDA) and 4, $4^{\prime}$-oxydiphthalic anhydride (ODPA) are preferred as semi-rigid dianhydride monomers, 4,4'-diaminodiphenylmethane (MDA), 2,2'-bis [4-(4-aminophenoxy) phenyl] propane (BAPP) and 3,4'-oxydianiline (3,4'-ODA) are used as semi-flexible diamine monomers. Many researches have been performed to adjust the molecular structures of polyimides to enhance processing, while keeping the thermo-oxidative stability of the material. Copolymerization is one of the most efficient ways to improve the processability of the polymer [27]. When a second dianhydride or diamine is introduced into the reaction, the symmetry and repetition of molecular structure is destroyed. Ultimately, the interaction between the rigid chains and crystallinity of the copolymer is reduced [34]. In literature, PMR-15 and LARC RP-46 polyimide homopolymers have been worked; however the effect of both MDA and 3,4'-ODA co-monomers on the processability of the copolyimide consisting these co-monomers has not been studied in detail [35].

In the present study, novel nadic end capped high temperature copolyimide adhesives, MDA-BTDA-ODA, were synthesized at various MDA and ODA compositions. The effect of diamine composition on thermal, mechanical and adhesion properties of the resulting copolymers was investigated. Changing the composition of PMR-15 by replacing 4, $4^{\prime}$-MDA with 3, $4^{\prime}$-ODA in increments, $25 \%, 50 \%$, and $75 \%$ was expected to reduce the rigidity or regularity of the backbone. Therefore, the processability and toughness of the polymer was aimed to be improved while maintaining the thermal stability.

\section{Experimental}

\subsection{Materials}

3,3',4,4'-benzophenonetetracarboxylic dianhydride (BTDA) (98\%), 3,4'-oxydianiline (3,4'-ODA) (98\%) and nadic anhydride (NA) (98\%) were purchased from Ivy Fine Chemicals. 4,4'-methylene dianiline (MDA) $(\geqslant 97.0 \%)$ was delivered from Fluka. $N, N$ - dimethyl formamide $(\geqslant 99.98 \%)$ was received from Aldrich. Methanol $(\geqslant 99.98 \%)$ was supplied by Merck. All chemicals were used as received without further purification. AVSIL 7PS pre-shrunk silica fabric was purchased from AVS Industries, LLC. 304 grade stainless steel alloy was used as the adherents. All the surfaces to be bonded were sanded using an automatic sanding pad with abrasive paper of grit size P80.

\subsection{Synthesis of polyimide polymers}

The synthesis of polyimides and copolyimides were carried out via a two-step method, which includes the preparation of polyamic ester (PAE) as a precursor along with thermal imidization process. The route for the synthesis of the copolyimide was explained in scheme 1 [36].

Four types of PAE samples with different MDA:ODA molar ratios (100:0, 75:25, 50:50, 25:75 and 0:100) were synthesized, namely PMR-15 prepolymer, PAE MDA:ODA [75:25], PAE MDA:ODA [50:50], PAE MDA: ODA [25:75] and LARC RP-46 prepolymer, respectively. PMR-15 prepolymer was prepared according to the procedure of Meador et al [37]. LARC RP-46 prepolymer was synthesized according to the procedure of Soucek et al [25]. Then, PAE samples were converted into the corresponding polyimides through thermal imidization. The mole ratio of NA:BTDA:(MDA + ODA) for the target molecular weight $\left(1500 \mathrm{~g} \mathrm{~mol}^{-1}\right)$ was calculated as 2: $\mathrm{n}:(\mathrm{n}+1)$ by using the Carother's equation $(\mathrm{n}=2.087)$. Take the synthesis of PAE MDA:ODA [50:50] for example: NA (3.28 g, $20 \mathrm{mmol})$ and BTDA $(6.72 \mathrm{~g}, 20.9 \mathrm{mmol})$ were refluxed in $18.14 \mathrm{~g}$ of methanol for $2 \mathrm{~h}$ at $70{ }^{\circ} \mathrm{C}$. At the reflux process, the solid chemicals dissolved forming a clear solution. After reflux, the solution was cooled to room temperature. Then, MDA (3.06 g, $15.4 \mathrm{mmol})$ and ODA (3.09 g, $15.4 \mathrm{mmol})$ were added into the solution. After that, the solution was stirred at room temperature until MDA and ODA were dissolved. At the end of the process, PAE resin solution was obtained. 
<smiles>O=C1OC2CCCC1C1CCCC21</smiles>

(NA)<smiles>COc1ccc(C(=O)c2ccc3c(c2)C(=O)OCC3)c(OC)c1</smiles>

MetOH $\downarrow$ Reflux, $70^{\circ} \mathrm{C}, 2 \mathrm{~h} \quad$ MetOH $\downarrow$ Reflux, $70^{\circ} \mathrm{C}, 2 \mathrm{~h}$

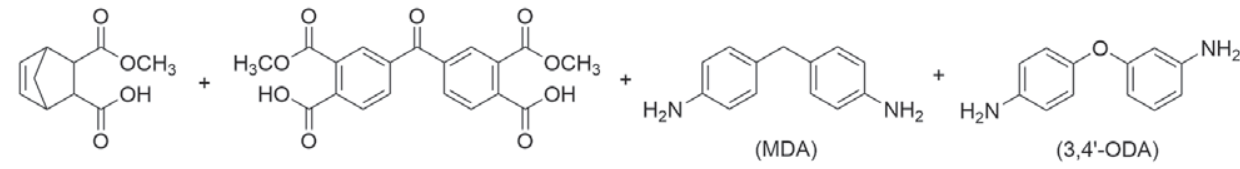

Room temperature $-150^{\circ} \mathrm{C}$

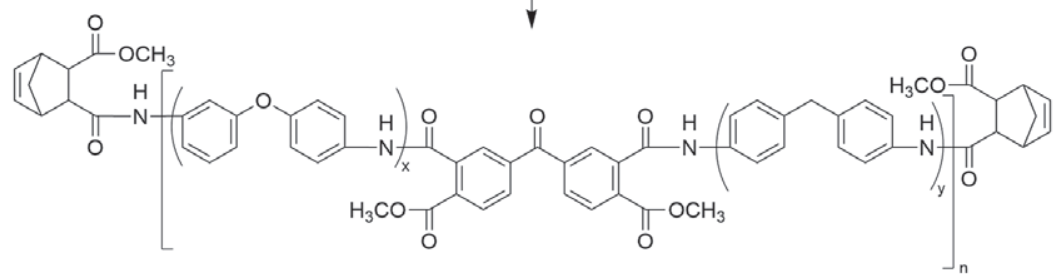

Amic ester prepolymer Imidization $\left(150^{\circ} \mathrm{C}-250^{\circ} \mathrm{C}\right)$


Reverse Diels-Alder Reaction $\left(250^{\circ} \mathrm{C}-316^{\circ} \mathrm{C}\right)$

\{<smiles>CCOc1cccc(C(C)C)c1</smiles><smiles>CCn1c(=O)c2ccc(C(=O)c3ccc4c(c3)C(=O)N(c3ccc(Cc5ccc(N(C)C)cc5)cc3)C4=O)cc2c(=O)n1-c1ccc(C(=O)c2ccc3ccccc3c2)cc1</smiles>
Cross-linking<smiles>CCCC(C)C1C=CC(C2=C(C(C)C)C(=O)N(c3cccc(O)c3)C2=O)C1</smiles>

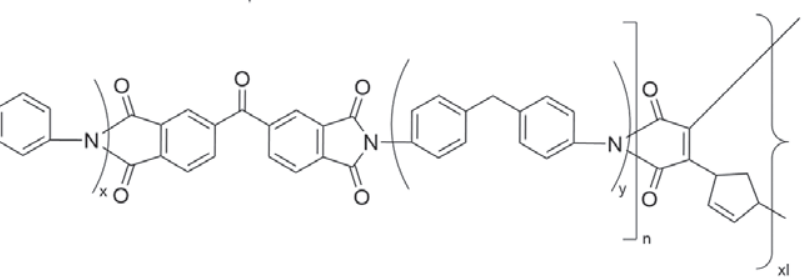

Thermally cross-linked ODA-BTDA-MDA copolyimide

Scheme 1. Reaction scheme for nadic end capped MDA-BTDA-ODA copolyimide.

Some of the resin solution was used as adhesive. PAE powder was also obtained from the resin solution by removing methanol through rotary evaporation at $35^{\circ} \mathrm{C}$ under vacuum. After removing the solvent, the resulting PAE foam was gently crushed to fine solids. 


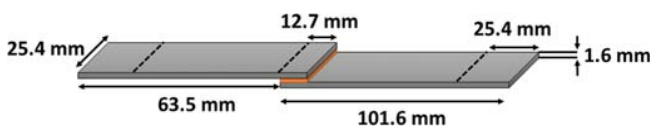

Figure 1. Dimensions of the single lap-joint specimen.

\subsection{Preparation of lap shear strength test specimens}

The lap shear strength test specimens were prepared in accordance with ASTM D1002 [38]. The size of the adherent was $101.6 \times 25.4 \times 1.6 \mathrm{~mm}$. Two pieces of stainless steel adherents were prepared and the surfaces of the adherents were sanded (figure 1). The sanded adherents were cleaned by acetone and dried at room temperature before bonding.

The adherents were degassed at $35^{\circ} \mathrm{C}$ for $30 \mathrm{~min}$ in a vacuum oven to remove bubbles after polyimide precursor solution had been spread. Two pieces of steel sheet adherents, which were gummed with prepolymer coating, were stuck together in such a manner to get an overlap of $12.7 \mathrm{~mm}$. The single lap-joint samples were anchored with a fixture, and they were placed into air circulation oven to undergo a stepwise imidization process. The adhesive was cured through thermal imidization by raising the temperature to 150, 200, 250, 275 and $316^{\circ} \mathrm{C}$, and the sample was held for $1 \mathrm{~h}$ at each of these temperatures.

\subsection{Characterization}

Infrared spectra (FT-IR) of the synthesized polyimide and copolyimide samples were recorded on a Perkin Elmer Spectrum One Spectrometer by using attenuated total reflection (ATR) probe with spectral resolution of $4 \mathrm{~cm}^{-1}$ in the frequency range of $650-4000 \mathrm{~cm}^{-1} .{ }^{1} \mathrm{H}$ NMR spectra of the prepolymer samples were recorded on Bruker AVANCE III $400 \mathrm{MHz}$ Liquid NMR Spectrometer using DMSO- $d_{6}$ as solvent.

The thermal gravimetric analyses (TGA) of polyimides were performed using Perkin Elmer Pyris 1 Thermal Gravimetric Analyzer. TGA curves were obtained at a heating rate of $10^{\circ} \mathrm{C} \mathrm{min}^{-1}$ under $\mathrm{N}_{2}$ atmosphere. The viscosity data of the prepolymer resins were obtained with a heating rate of $5^{\circ} \mathrm{C} \mathrm{min}^{-1}$ from room temperature to $375^{\circ} \mathrm{C}$ using shear for liquid holder of Metravib +450 model Dynamic Mechanical Analyzer under $1 \mathrm{~Hz}$ frequency and $5 \times 10^{-6} \mathrm{~m}$ displacement. Dynamic thermo-mechanic analysis (DMA) of silica fabric/resin tape samples was performed by using Metravib +450 Dynamic Mechanical Analyzer with a heating rate of $10{ }^{\circ} \mathrm{C} \mathrm{min}^{-1}$ from room temperature to $430^{\circ} \mathrm{C}$ at $1 \mathrm{~Hz}$ frequency. The storage modulus $\left(\mathrm{E}^{\prime}\right)$ and tangent of loss angle $(\tan \delta)$ were obtained as a function of scanning temperature using tension mode. Silica fabric/resin samples were prepared by thermal imidization of [PAE powder:DMF] solution ( 50 weight $\%)$ impregnated silica fabrics.

Lap shear strength tests of bonded samples were carried out in accordance with ASTM standard D1002 by using Zwick tensile tester with a load cell of $5 \mathrm{kN}$ at a constant crosshead speed of $1.0 \mathrm{~mm} \mathrm{~min}{ }^{-1}$. All tests were conducted under the laboratory environment at room temperature $\left(23 \pm 3{ }^{\circ} \mathrm{C}\right.$ and $30 \pm 5 \%$ relative humidity). Three specimens were tested to obtain an average value of the lap shear strength. The fracture morphology of these adhesive joints was examined using a stereo microscope (Zeiss, Stemi 2000) and an optic microscope microscope (Zeiss, Axioskop 2 Mat).

\section{Results and discussion}

\subsection{Spectroscopic analysis}

The synthesized polyimides (PIs) were characterized by vibrational spectroscopy (figure 2). The formation of polyimide is confirmed by the characteristic absorption bands of the imide ring observed at $1778 \mathrm{~cm}^{-1}$, $1707 \mathrm{~cm}^{-1}, 718 \mathrm{~cm}^{-1}$ and $1370 \mathrm{~cm}^{-1}$. These signals correspond to the asymmetrical stretching, symmetrical stretching, and flexural vibration of $\mathrm{C}=\mathrm{O}$ and stretching vibration of $\mathrm{C}-\mathrm{N}$, respectively.

PIs are infusible and cannot be melted because of their rigid backbone. Therefore, structural identification of PIs was attempted by ${ }^{1} \mathrm{H}$ NMR analysis of polyamic ester precursors (supporting information figures $\mathrm{S} 1-5$ is available online at stacks.iop.org/MRX/5/105305/mmedia). The absence of any carboxylic acid signal in the ${ }^{1} \mathrm{H}$ NMR spectra proves the formation of methyl ester of polyamic ester (PAE) instead of polyamic acid itself. Since PAE consists of polymeric groups (MDA and ODA), the ${ }^{1} \mathrm{H}$ NMR spectra are quite complex. The signals are broad due to presence of repeating polymeric units. The signal integrals are not as sharp as expected. The general interpretation of spectra can be as follows:

The signals at low field, especially the singlet signal at around $10 \mathrm{ppm}$ belong to the protons of secondary amine groups. The multiplet signal between 6-8 ppm is due to the phenyl moieties on the main chain backbone. The doublets at around 6 ppm belong to double bond of the bicyclic moiety at the ends. The signal between 


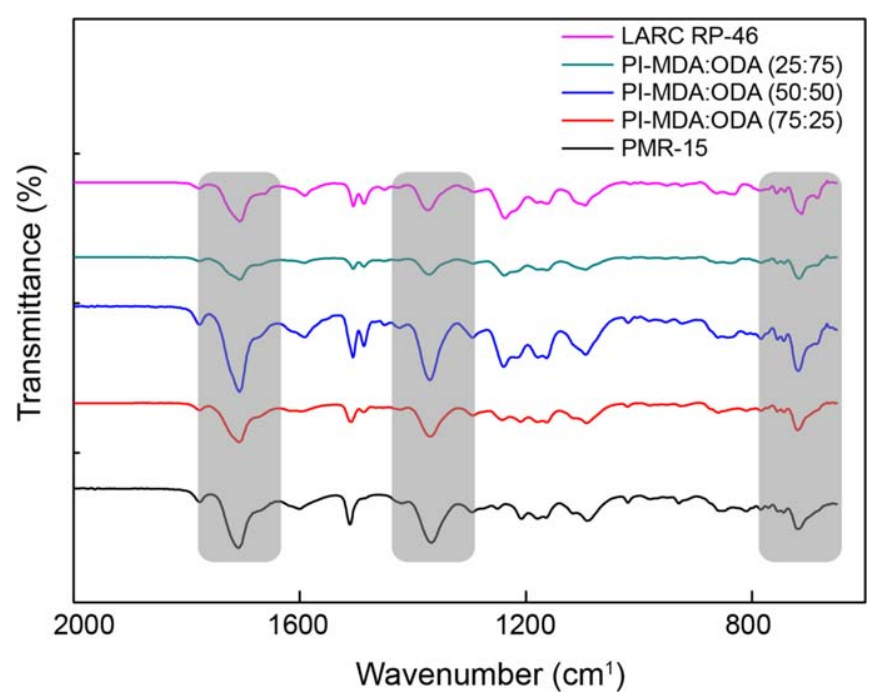

Figure 2. FTIR spectra of PMR-15, LARC RP-46 and cured PI MDA:ODA copolyimide samples.

3-4 ppm stands for methine $(\mathrm{CH})$ groups of the bicyclic moiety. In all copolymers having MDA as the repeating unit, the characteristic singlet signal at around $3.6 \mathrm{ppm}$ may stand for the methylene group of the MDA repeating unit. The other singlet signals at around $4.0 \mathrm{ppm}$ are due to the methyl protons of ester groups. The interpretation of these singlet signals are in accordance with the spectrum of PMR-15 in article prepared by Hammadi et al [39]. The relation of the area under characteristic methylene singlet of MDA and the percentage of MDA has been questioned; however satisfactory results have not been obtained due to the complexity of the NMR spectra. A decrease in the intensity of methylene signal has been observed from 100\% MDA to 0\% MDA homopolymer. The high field signal at around $1.6 \mathrm{ppm}$ belongs mainly to the bridgehead protons of the bicyclic end group.

PAE MDA:ODA [100:0] (PMR-15 Prepolymer): ${ }^{1} \mathrm{H}$ NMR (400 MHz, DMSO- $\left.d_{6}\right) \delta 10.51$ and 9.60 (s, amine), 8.22-6,56 (m, phenyl), 6.20 (d, double bond of bicyclic), 3.81-2.95 ( $\mathrm{m}$, bicyclic $\mathrm{CH}$ ), 3.98 (s, methoxy), 3.62 (s, MDA $\mathrm{CH}_{2}$ ), 1.58 (s, bridge head $\mathrm{CH}_{2}$ ). (supporting information figure $\mathrm{S} 1$ ).

PAE MDA:ODA [75:25]: ${ }^{1} \mathrm{H}$ NMR (400 MHz, DMSO- $\left.d_{6}\right) \delta 10.43$ and 9.82 (s, amine), 8.16-6.59 (m, phenyl), 6. 17 (double bond of bicyclic), 3.77-3.06 (m, bicyclic $\mathrm{CH}$ ), 3.98 (s, methoxy), 3.48 (s, $\mathrm{MDA} \mathrm{CH}_{2}$ ), 1.58 (s, bridge head $\mathrm{CH}_{2}$ ). (supporting information figure $\mathrm{S} 2$ ).

PAE MDA:ODA [50:50]: ${ }^{1} \mathrm{H}$ NMR (400 MHz, DMSO- $\left.d_{6}\right) \delta 10.46$ and 9.82 (s, amine), 8.15-6,6 (m, phenyl), 6.17 (d, double bond of bicyclic), 3.85-3.04 (m, bicyclic CH), 3.98 (s, methoxy), 3.61 (s, $\mathrm{MDA} \mathrm{CH}_{2}$ ), 1.58 (s, bridge head $\mathrm{CH}_{2}$ ). (supporting information figure $\mathrm{S} 3$ ).

PAE MDA:ODA [25:75]: ${ }^{1} \mathrm{H}$ NMR (400 MHz, DMSO- $\left.d_{6}\right) \delta 10.26$ and 9.83 (s, amine), 8.14-6.57 (m, phenyl), 6.13 (double bond of bicyclic), 3.75-3.01 (m, bicyclic $\mathrm{CH}), 3.98$ (s, methoxy $\left.\mathrm{CH}_{2}\right), 3.62\left(\mathrm{~s}, \mathrm{MDA} \mathrm{CH}_{2}\right), 1.58(\mathrm{~s}$, bridge head $\mathrm{CH}_{2}$ ). (supporting information figure $\mathrm{S} 4$ ).

PAE MDA:ODA [0:100] (LARC RP-46 Prepolymer): 1H NMR (400 MHz, DMSO-d6) $\delta 10.52$ and 9.78 (s, amine), 8.31-6.41 (m, phenyl), 6.19 (d, double bond of bicyclic), 3.84-3.00 ( $\mathrm{m}$, bicyclic $\mathrm{CH}$ ), 1.59 (s, bridge head $\mathrm{CH} 2$ ). (supporting information figure S5).

\subsection{Thermal analysis}

PIs have high temperature resistance because of their heterocyclic and rigid structure. The thermal stability of most PIs were assessed by thermo-gravimetric analysis [40, 41]. The TGA thermograms of the synthesized polyimide and copolyimide adhesives are illustrated in figure 3 . There is almost no weight loss up to $400{ }^{\circ} \mathrm{C}$. Therefore, the imidization process is reasonably complete. The $5 \%$ and $10 \%$ mass loss temperatures of the polyimide samples are in range of $442.0{ }^{\circ} \mathrm{C}-463.0{ }^{\circ} \mathrm{C}$ and $490.6{ }^{\circ} \mathrm{C}-500.6{ }^{\circ} \mathrm{C}$, respectively. The results show that the thermal stability of the copolyimide samples remains generally stable due to the presence of reactive benzylic hydrogens in the structure [42]. These hydrogens lead to formation of free radicals upon cleavage of $\mathrm{C}-\mathrm{H}$ bonds. Therefore, additional crosslinking may occur before degradation [43].

\subsection{Dynamic mechanical properties}

Viscoelasticity of polyimide samples was analyzed by running loss tangent $(\tan \delta)$ measurements via Dynamic Mechanic Analyzer. Tan $\delta$ is the ratio of the loss modulus ( $\left.\mathrm{E}^{\prime \prime}\right)$ to storage modulus ( $\left.\mathrm{E}^{\prime}\right)$ for materials. 


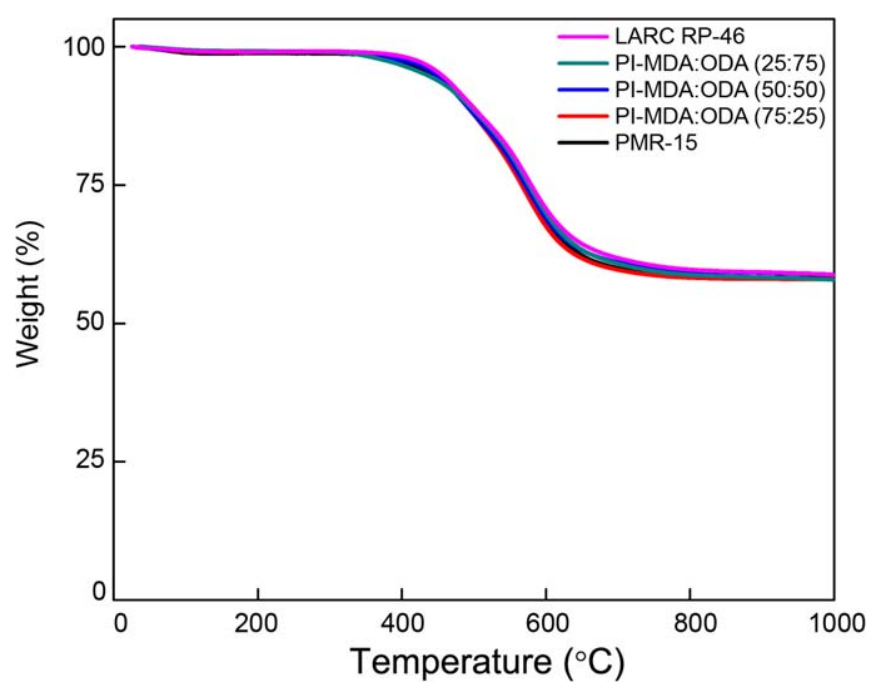

Figure 3. TGA thermograms of the LARC RP-46 and PMR-15, and synthesized copolyimides with different MDA:ODA ratios.

Table 1. $T_{g}$ values of PMR-15, LARC RP-46 and synthesized copolyimides with different MDA:ODA ratios.

\begin{tabular}{lcc}
\hline Polyimides & $T_{g}\left({ }^{\circ} \mathrm{C}\right)$ by tan $\delta$ & $T_{g}\left({ }^{\circ} \mathrm{C}\right)$ by $\mathrm{E}^{\prime}$ \\
\hline PMR-15 & 395 & 357 \\
PI MDA:ODA [75:25] & 394 & 330 \\
PI MDA:ODA [50:50] & 402 & 330 \\
PI MDA:ODA [25:75] & 401 & 331 \\
LARC RP-46 & 388 & 332 \\
\hline
\end{tabular}

$$
\tan \delta=\frac{E^{\prime \prime}}{E^{\prime}}
$$

Materials display viscoelastic liquid-like behavior when $\tan \delta>1$. On the other hand, they behave like viscoelastic solids when $\tan \delta<1$. Polymer adhesives having $\tan \delta$ values $>1$ offer enhanced wetting in composite materials even under low pressures $(<2 \mathrm{MPa})$. However, high pressures are required for those adhesives having $\tan \delta<1$ in order to achieve wetting [44]. The same argumentation is also valid for wetting of adherent surfaces. Glass transition temperature $\left(T_{g}\right)$ changes from the glassy into the rubber-elastic state at the maximum $\tan \delta$ value. The temperature around a steep decrease in the storage modulus is also used as another way to determination of glass transition temperature. According to the DMA results illustrated in table $1, T_{g}$ values of the samples remain nearly stable. The reason of this situation may originate from the steric hindrance of the methylene group of MDA. In comparison to ODA ether group, MDA comonomer leads to the formation of more steric hindrance around methylene group. Moreover, the interaction between hydrogen atoms of methylene and phenyl blocks the movement of the benzene structures [45]. Therefore, the movement of the segments gets harder. And finally, $T_{g}$ remains nearly unchanged.

The peak value of $\tan \delta$ indicates the damping property of materials. In figure 4 , the maximum $\tan \delta$ value of LARC RP-46 is higher than that of PMR-15 because of the presence of flexible ether units in the structure of LARC RP-46. On the other hand, damping properties of [MDA:ODA] polyimide copolymers are higher than those of both PMR-15 and LARC RP-46 homopolymers. The situation can be related to the decrease in the rigidity of the polymers due to the disruption of the molecular symmetry.

\subsection{Processability}

Ether groups in polymer backbone act as a swivel that enhances the flexibility of the polymer chain. The ratio of ether group (ODA\%) in the backbone affects the processability of the polyimide resins. As illustrated in figure 5 , dynamic viscosity modulus of the polyimides decreases with the increasing ODA\% content up to 75\% ODA mol ratio. However, it increases suddenly at 100\% ODA content (LARC RP-46) because of the increase in molecular symmetry and regularity of the polymer structure. As it is indicated in the figure, copolyimides having $50 \%$ and 75\% ODA are more processable than PMR-15 and LARC RP-46. Therefore, more processable PI resins can be obtained by decreasing the regularity of the polymer's molecular structure, and incorporation of flexible ether- 


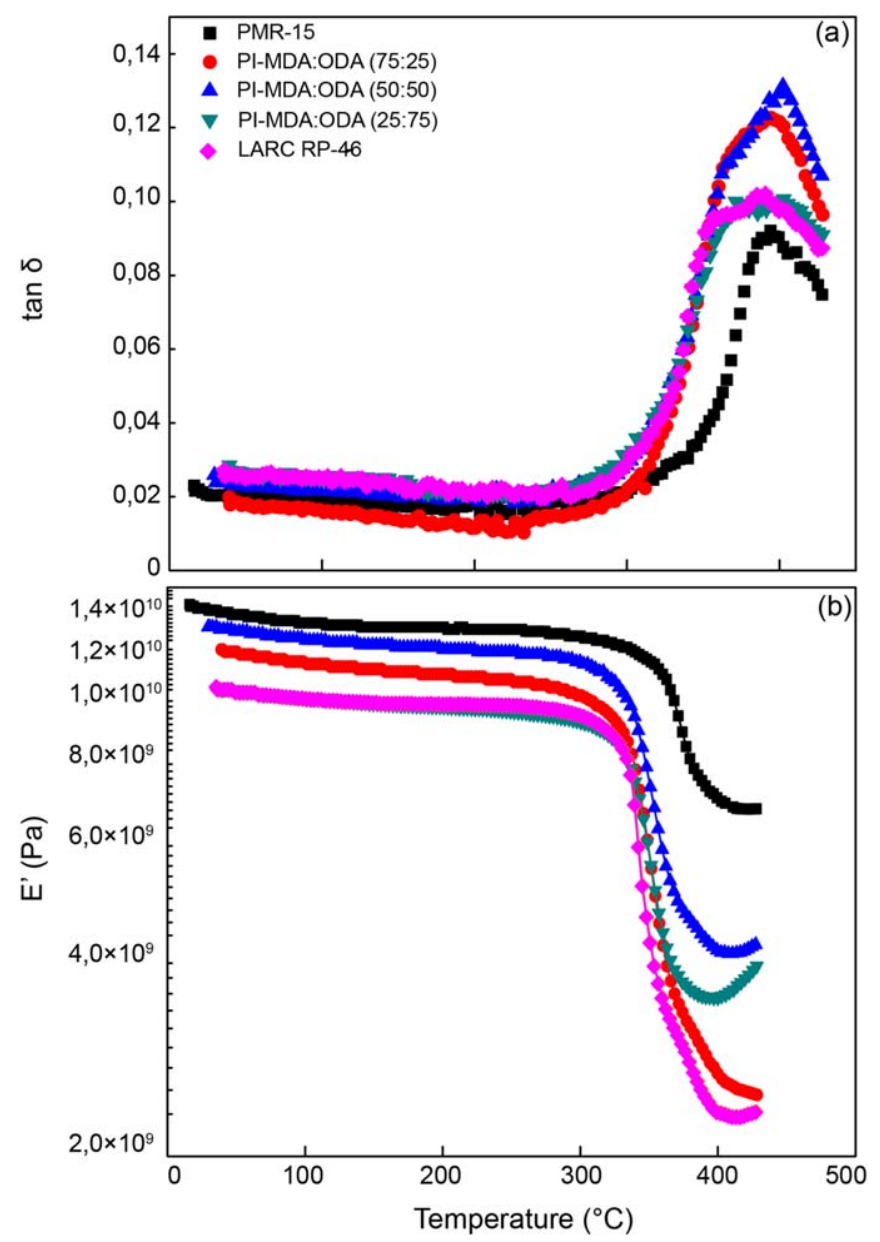

Figure 4. (a) $\tan \delta$ versus temperature curve and (b) $\mathrm{E}^{\prime} \delta$ versus temperature curves of PMR-15, LARC RP-46 and the synthesized copolyimides with different MDA:ODA ratio.

bridged aromatic segments into polyimide backbone. On the other hand, the increase in dynamic viscosity with increasing temperature originates from the formation of cross-linking [36].

\subsection{Adhesion performance}

Depending on different application requirements and fracture modes, several mechanical measurement techniques for assessment of the adhesion performance can be used, such as double cantilever beam (DCB) tests and single-lap shear tests. Of these, double cantilever beam tests are one of the frequently preferred fracture tests in mode-I because they are easy to be implemented and require simple samples. However, besides the difficulty of measuring crack propagation in DCB tests, the determined toughness of an adhesive can vary considerably depending on the elastic moduli and approaches [46]. On the other hand, despite its tendency to exhibit high variability, the single-lap joint configuration is widely used in industry to determine shear strength in mode-II fracture due to economical and practical advantages of the method. However, it is to be noted that the shear strength is 'apparent' due to non-uniform stress field that occurs along the bondline in a lap shear joint according to the shear lag concept suggested by Volkersen in 1938 [47]. The concept discloses the transfer of the load between two elements joined together by separate connections, such as mechanical fasteners, or a continuous layer such as an adhesive. Nevertheless, Volkersen also propose that uniform stress field could be a reasonable assumption if the adherends are sufficiently stiffer and thicker than the adhesive. In this study, the adhesion performances of the PIs were determined by single-lap shear test [38]. In order to achieve optimum bonding performance, the factor of molar ratio of the diamine monomers was studied. The results of single lap shear stress tests of the PI resins are shown in figure 6. The maximum shear strength was achieved by equimolar mixture of MDA:ODA molar ratio that can be explained by reaching optimum mechanical strength and wetting capability of the copolymer, and this result is in consistent with the literature [34]. The increase in ODA content in the PI copolymers leads to the increase in fluidity that causes the enhancement of polymer-adherent interaction. On the other hand, mechanical strength of the cured resin decreases with the incorporation of ether groups into the polymer backbone $[32,48,49]$. Therefore, the effect of wettability and mechanical strength on 


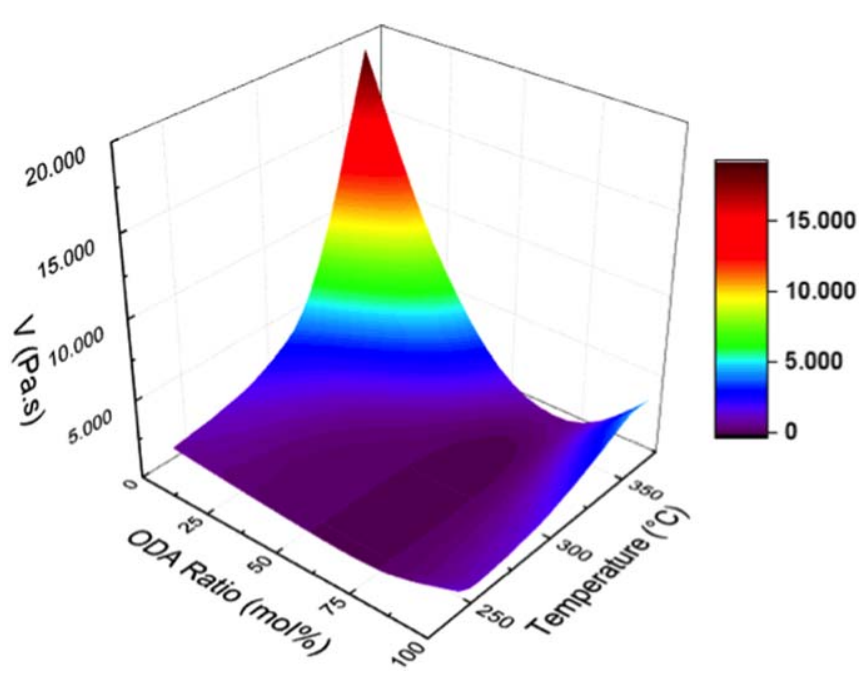

Figure 5. Dynamic viscosity modulus curves of PMR-15, LARC RP-46 and synthesized copolyimide samples with different MDA: ODA ratio.

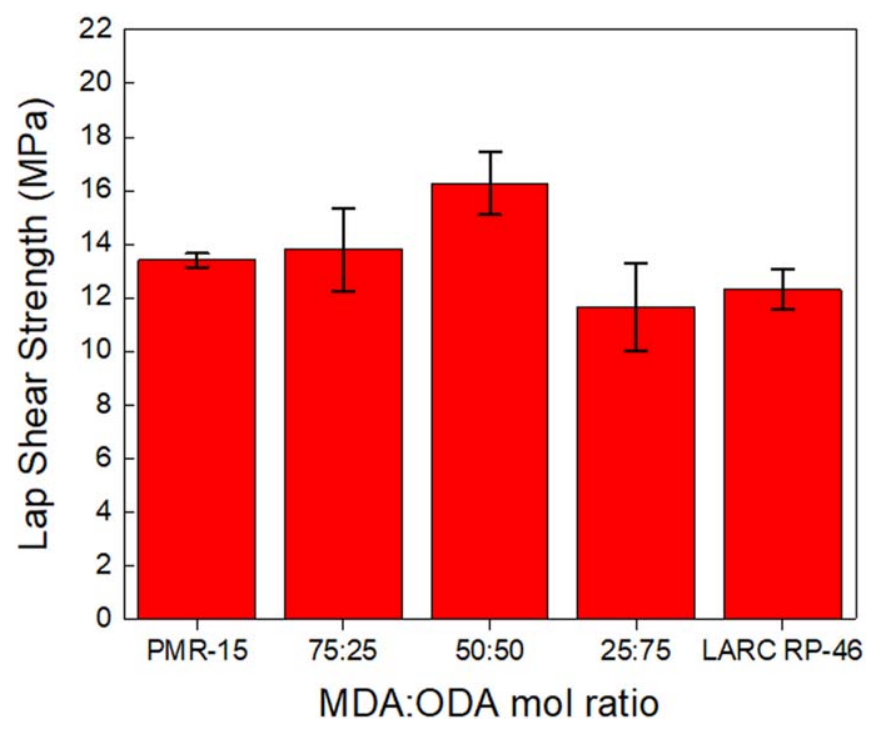

Figure 6. Adhesion strengths of polyimide adhesives with different molar ratios of MDA:ODA diamine.

the adhesive performance was balanced at 50:50 (MDA:ODA) molar ratio. The adhesion strength values of the copolyimides are nearly in the same range with MDA-BAPP-BTDA co-polyimide synthesized by Li et al [34]. The authors modify the adhesion strength of the copolyimide by changing the viscosity of the polymer with different monomer ratios. If the effect of temperature is taken into consideration, it is expected that the relative performance of the adhesives will change significantly at an operating temperature higher than the glass transition temperature. Xu and Jinrong's group reported that the rigidity of adhesives decline due to the gradual increase in macromolecular motion with the increase of the temperature around $\mathrm{T}_{\mathrm{g}}[50,51]$. Therefore, the shear strenght of the adhesives are supposed to decrease.

The image showing the failure mode of the copolyimide adhesives is given in figure 7(a). Micrographs of interfacial fractured surfaces at the middle of single lap joints are shown in figures 7(b)-(c). The failures for single lap joints were started at the interface between the adherent surface and the adhesive. In fact, both of cohesive and interfacial failures are observed as a result of propagation of cracks through the adhesive.

The morphology of fractured joints of PI MDA:ODA [50:50] adhesive lap joint was investigated via SEM. Figures 8(a)-(c) shows the river-like pattern, which was emanated perpendicular to the shear direction and crack formation. The cup and cone type morphology of surfaces between the cracks reveals the cohesive and ductile nature of the fracture $[49,52]$. 

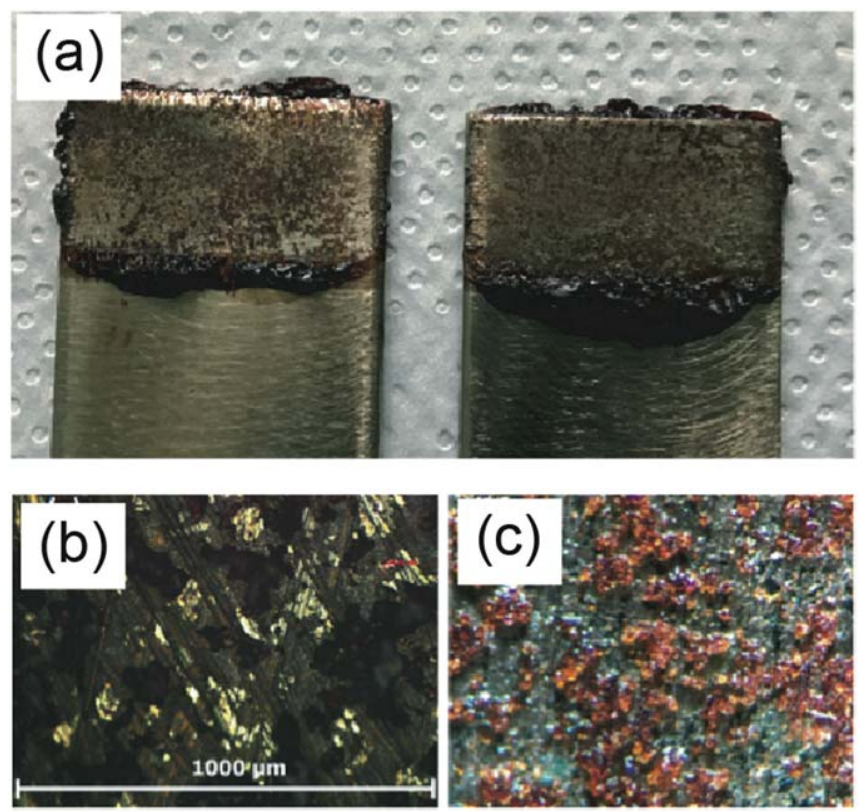

Figure 7. (a) Failure mode of the copolyimide samples, (b) stereo microscope image of the interfacial fractured surface of single lap joint, and (c) microscope image of the interfacial fractured surface of single lap joint.
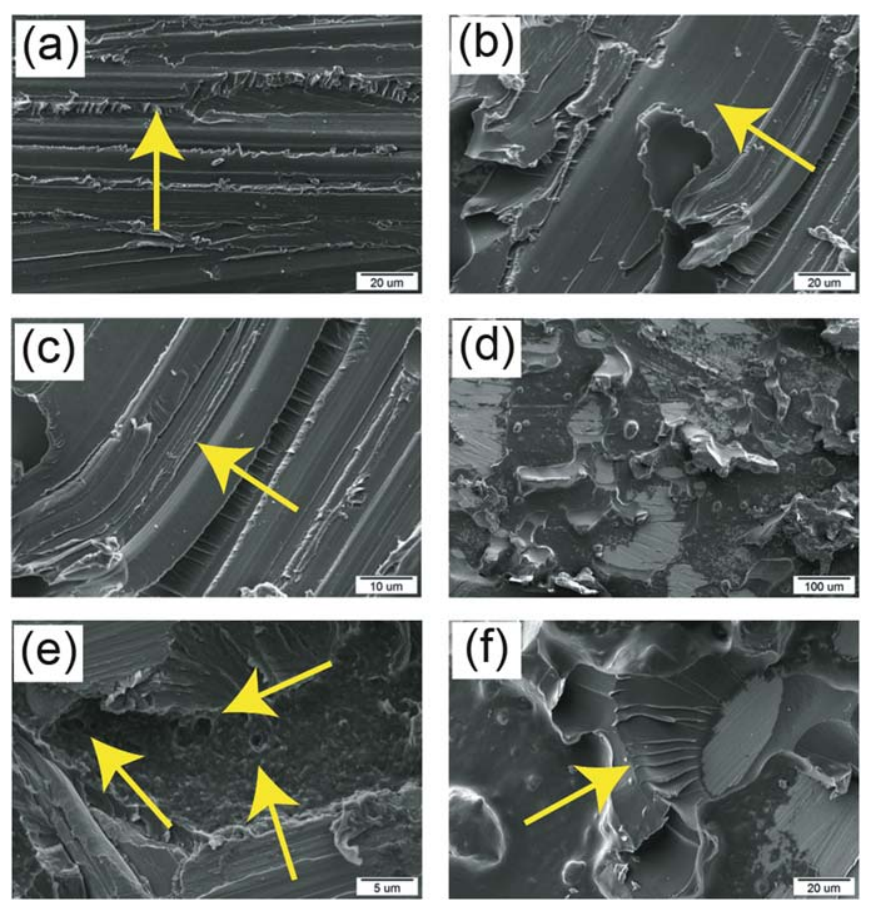

Figure 8. SEM micrographs of fractured joints of PI MDA:ODA [50:50] (a)-(c) shear directions, (d) shear cup, (e) microvoids, and (f) shear delamination.

The plastic deformation mechanism could be observed from the micrographs such that cup and cone formation with microvoids are the signs of ductile fracture [53]. While figure 8(d) demonstrates the formation of shear cups; figure 8(e) shows the microvoids throughout the cracks. Microvoids coming from the evaporation of solvent may be the reason for the failure formation. Cohesive type fracture is a desirable condition in adhesive applications, because of the stronger interaction between adherent surface and adhesive. So, greater effort is required to separate them [52]. Lastly, figure 8(f) indicates the cohesive fracture coming from shear delamination with cup and cone formation. Considering these fractographic investigations, as-synthesized PI adhesives are preferable due to their cohesive and ductile fracture behavior. 


\section{Conclusion}

MDA-BTDA-ODA copolyimide novel adhesives with nadic end cap were successfully synthesized by a two-step method, including the preparation of polyamic ester prepolymer and thermal imidization. They were structurally characterized by FTIR and ${ }^{1} \mathrm{H}$ NMR Thermal stability, dynamic mechanical properties and adhesion performance of the polyimides were investigated. The copolymers have considerable thermal endurance. The DMA results demonstrate that the synthesized copolyimide exhibits higher processing capability than the commercial PMR-15. They lose only $\% 10$ weight when heated to $500{ }^{\circ} \mathrm{C}$. The glass transition temperatures of all copolymers have been found at around $400^{\circ} \mathrm{C}$. The thermoset copolyimides exhibit promising adhesion performance. The highest adhesion strength at room temperature was $16.3 \mathrm{MPa}$. The processing capability of the polymer increases with the increasing ODA comonomer content up to 75\% ODA mol ratio. Thus, the polyimide resins possess a significant processability with the introduction of flexible ether bridged ODA monomer into the backbone and reducing the regularity of polymer structure. MDA:ODA [50:50] polyimide has been found to have optimum processability and maximum adhesion performance. And also, it is more processable than both PMR-15 and LARC RP-46 polyimides.

\section{ORCID iDs}

\section{Mustafa M Demir (iD https://orcid.org/0000-0003-1415-605X}

\section{References}

[1] Cole G and Sherman A 1995 Light weight materials for automotive applications Mater. Charact. 35 3-9

[2] Immarigeon J P et al 1995 Lightweight materials for aircraft applications Mater. Charact. 35 41-67

[3] Matsuzaki R, Shibata M and Todoroki A 2008 Reinforcing an aluminum/GFRP co-cured single lap joint using inter-adherend fiber Composites Part A: Applied Science and Manufacturing 39 786-95

[4] Naito K, Onta M and Kogo Y 2012 The effect of adhesive thickness on tensile and shear strength of polyimide adhesive International Journal of Adhesion and Adhesives 36 77-85

[5] Adams R D and Wake W C 1984 Structural Adhesive Joints in Engineering (Dordrecht: Springer) pp 1-13

[6] Da Silva L F M, Öchsner A and Adams R D 2011 Handbook of Adhesion Technology (Berlin: Springer) pp 1-7

[7] Marques E A S et al 2015 Adhesive joints for low- and high-temperature use: an overview J. Adhes. 91 556-85

[8] Hornung M and Hajj M 2009 Structural bonding for lightweight construction Light Metals Technology 618-9 49-56

[9] Song R, Muliana A H and Palazotto A 2016 An empirical approach to evaluate creep responses in polymers and polymeric composites and determination of design stresses Compos. Struct. 148 207-23

[10] Saeed M B and Zhan M S 2007 Adhesive strength of nano-size particles filled thermoplastic polyimides. Part-I: multi-walled carbon nano-tubes (MWNT)-polyimide composite films International Journal of Adhesion and Adhesives 27 306-18

[11] Scola D A 2001 Polyimide resins ASM Handbook vol 21 - Composites (Ohio: ASM International) pp 263-308

[12] Huo H T et al 2011 Synthesis of phthalic end-capped copolyimides and their adhesive properties High Perform. Polym. 23 374-83

[13] Yi L, Huang W and Yan D 2016 Polyimides with side groups: synthesis and effects of side groups on their properties Journal of Polymer Science Part A: Polymer Chemistry 55 533-59

[14] Ding M 2007 Isomeric polyimides Prog. Polym. Sci. 32 623-68

[15] Volksen W, Miller R D and Dubois G 2009 Low dielectric constant materials Chem. Rev. 110 56-110

[16] Ghosh M K and Mittal K L 1996 Polyimides: Fundamentals and Applications (New York: Marcel Dekker Inc) pp 7

[17] Serafini T T, Delvigs P and Lightsey G R 1972 Thermally stable polyimides from solutions of monomeric reactants J. Appl. Polym. Sci. 16 905-15

[18] Castelli M G, Sutter J K and Benson D 1998 Thermomechanical fatigue durability of T650-35/PMR-15 sheet molding compound Symposium on Time Dependent and Non-Linear Effects in Polymers and Composites

[19] Lu Y C et al 2010 High temperature nanoindentation of PMR-15 polyimide Experimental Mechanics 50 491-9

[20] Ratta V et al 1999 A melt-processable semicrystalline polyimide structural adhesive based on 1, 3-bis (4-aminophenoxy) benzene and 3, 3', 4, 4'-biphenyltetracarboxylic dianhydride Polymer 40 1889-902

[21] Rozhanskii I, Okuyama K and Goto K 2000 Synthesis and properties of polyimides derived from isomeric biphenyltetracarboxylic dianhydrides Polymer 41 7057-65

[22] Saeed M B and Zhan M S 2007 Adhesive strength of partially imidized thermoplastic polyimide films in bonded joints International Journal of Adhesion and Adhesives 27 9-19

[23] Wilson D 1988 PMR- 15 processing, properties and problems - a review Br. Polym. J. 20 405-16

[24] Pater R P 1991 The $316^{\circ} \mathrm{C}$ and $371^{\circ} \mathrm{C}$ composite properties of an improved pmr polyimide Proc. of the 36 th Int. SAMPE Symp. : p. 78

[25] Soucek M D and Pater R H 1993 The effects of curing temperature on deformation and fracture toughness in thin films of LaRC ${ }^{\mathrm{TM}} \mathrm{RP} 46$ polyimide Journal of Plastic Film \& Sheeting $967-79$

[26] Hou T H et al 1996 Processing and properties of IM7/LARC(TM)-RP46 polyimide composites High Perform. Polym. $8491-505$

[27] Chao M et al 2012 Synthesis and properties of semicrystalline copolyimides based on 4,4'-diaminodiphenylether and 1,3-Bis(4aminophenoxy) benzene Journal of Macromolecular Science, Part B 51 2003-14

[28] Chen C, Qin W and Huang X 2008 Synthesis and characterization of novel polyimides derived from 1, 4-Bis (4aminophenoxymethylene) cyclohexane (BAMC) and two aromatic dianhydrides Journal of Macromolecular Science, Part B: Physics 47 783-93

[29] Chun B-W 1994 Preparation and characterization of organic-soluble optically transparent polyimides from alicyclic dianhydride, bicyclo [2.2.2]-oct-7-ene-2, 3, 5, 6-tetracarboxylic dianhydride Polymer 35 4203-8 
[30] Gao J P and Wang ZY 1995 Synthesis and properties of polyimides from 4, 4'-binaphthyl-1, 1', 8, 8'-tetracarboxylic dianhydride Journal of Polymer Science Part A: Polymer Chemistry 33 1627-35

[31] Han Y, Fang X Z and Zuo XX 2010 The influence of molecular weight on properties of melt-processable copolyimides derived from thioetherdiphthalic anhydride isomers J. Mater. Sci. 45 1921-9

[32] Pater R and Morgan C 1988 Interpenetrating polymer network approach to tougher and more microcracking resistant high temperature polymers SAMPE J 24 25-32

[33] Tamai S, Yamaguchi A and Ohta M 1996 Melt processible polyimides and their chemical structures Polymer 37 $3683-92$

[34] Li D X et al 2015 Synthesis and characterization of a novel high-temperature structural adhesive based on MDA-BAPP-BTDA Copolyimide Journal of Macromolecular Science Part a-Pure and Applied Chemistry 52 540-7

[35] Liaw D-J et al 2012 Advanced polyimide materials: syntheses, physical properties and applications Prog. Polym. Sci. 37 907-74

[36] Simone CD et al 2005 Some aspects of the cure of RP-46, a nadic end-capped polyimide, and phenyl nadimide and bis-nadic-3,4'-ODA model compounds High Perform. Polym. 17 51-72

[37] Meador M A B, Johnston J C and Cavano P J 1997 Elucidation of the cross-link structure of nadic-end-capped polyimides using NMR of 13C-labeled polymers Macromolecules 30 515-9

[38] International A 2010 Standard Test Method for Apparent Shear Strength of Single-lap-joint Adhesively Bonded Metal Specimens by Tension Loading (Metal-to-Metal) (West Conshohocken: ASTM international)

[39] Milhourat-Hammadi A et al 1994 NMR study of PMR-15 prepolymerization steps Journal of Polymer Science Part A: Polymer Chemistry 32 203-17

[40] Lee M-H et al 1999 Studies on imidization behaviors of differently processed samples of poly (imide-alt-amic ester) prepared from MDPM and 6FDA Macromolecules 32 2378-81

[41] Turk M J et al 1999 Evaluation of the thermal oxidative stability of polyimides via TGA techniques Journal of Polymer Science Part A Polymer Chemistry 37 3943-56

[42] Alston W 1992 Structure-to-property relationships in addition cured polymers. IV. Correlations between thermo-oxidative weight losses of norbornenyl cured polyimide resins and their composites Symposium on Advances in Polymer Matrix Composites https:/ / ntrs. nasa.gov/archive/nasa/casi.ntrs.nasa.gov/19920010797.pdf

[43] Xie W, Pan W-P and Chuang K C 2001 Thermal characterization of PMR polyimides Thermochimica Acta 367-368 143-53

[44] Gao W 1994 Modern Testing Technology for Polymer Materials (Beijing: Beijing University Press of Aeronautics and Astronautics)

[45] Yu-wei P et al 2012 Influence of steric hindrance between hydrogen atoms of linkage groups and adjacent phenyls on properties of polyimide Chemical Research in Chinese Universities 28 926-30 http://www.cjcu.jlu.edu.cn/hxyj/EN/abstract/abstract15526.shtml\#

[46] Dastjerdi A K, Tan E and Barthelat F 2013 Direct measurement of the cohesive law of adhesives using a rigid double cantilever beam technique Exp. Mech. 53 1763-72

[47] Volkersen O 1938 Die Nietkraft Verteilung in zugbeanspruchten Nietverbindungen mit kon- stantenLaschenquerschnitten Luftahrgorschung 15 41-7

[48] Furukawa N, Yamada Y and Kimura Y 1997 Lap shear bond strength of thermoplastic polyimides and copolyimides High Perform. Polym. $917-31$

[49] Kadiyala A K, Sharma M and Bijwe J 2016 Exploration of thermoplastic polyimide as high temperature adhesive and understanding the interfacial chemistry using XPS, ToF-SIMS and Raman spectroscopy Mater. Des. 109 622-33

[50] Wu J R et al 2012 Changes in the viscoelastic mechanisms of polyisobutylene by plasticization Macromolecules 45 8051-7

[51] Xu B and McKenna G B 2011 Evaluation of the Dyre shoving model using dynamic data near the glass temperature J. Chem. Phys. 134 $1-7$

[52] Kadiyala A K and Bijwe J 2016 Investigations on performance and failure mechanisms of high temperature thermoplastic polymers as adhesives International Journal of Adhesion and Adhesives 70 90-101

[53] Callister W D 2010 Materials Science and Engineering An Introduction (New York: John Wiley \& Sons, Inc) 